\title{
Efforts to explain low-energy nuclear reactions
}

\author{
Edmund Storms
}

Received: 8 August 2013 /Revised: 9 September 2013 / Accepted: 16 September 2013 / Published online: 30 October 2013

(C) Springer-Verlag Berlin Heidelberg 2013

The phenomenon called "cold fusion" or "low-energy nuclear reaction" (Storms 2007) has now reached a stage when explanations are attracting attention. The major experimental work was summarized by Storms in 2010 (Storms 2010). Now, Krivit has cited "errors" in this review which he believes might guide an explanation in the wrong direction. He notes that heat, detected using light hydrogen and when transmutation occurred, was frequently overlooked in this review. In addition, in his opinion, the claim for $\mathrm{d}+\mathrm{d}={ }^{4} \mathrm{He}$ being the major source of heat is not supported by the cited evidence.

Because the conclusion reached by Krivit (2013) is a direct challenge to what Storms (2010) reviewed in the cited paper, a summary of the evidence is required. Although many studies resulting in heat production using deuterium did not attempt to measure helium, over 16 independent studies using numerous samples found that helium was present when energy production was detected and some measurements found no helium when no extra energy was detected. Three independent studies measured the energy/He ratio, which can be summarized as $25 \pm 5 \mathrm{MeV} / \mathrm{He}$. All other known reactions that produce helium result in less energy/helium atom. For example, the proposed reaction of ${ }_{3}^{6} \mathrm{Li}+2 \mathrm{n}=2 \mathrm{He}+\mathrm{e}^{-}$produces only 13.4 MeV/He. Readers must decide for themselves if this is enough evidence to go forward in search for an explanation based on helium as the major nuclear product before additional studies are made.

All isotopes of hydrogen, presumably, are involved in the cold fusion process. Most information comes from the use of deuterium because this isotope is most studied. In addition, many different nuclear reactions, including tritium formation (Storms 2007) and transmutation (Srinivasan et al. 2011) are

Communicated by: Sven Thatje

E. Storms $(\bowtie)$

KivaLabs, 2140 Paseo Ponderosa, Santa Fe, NM, USA

e-mail: storms2@ix.netcom.com observed. Although important, these are "side issues" to heat production because they have not been found to occur at a rate sufficient to make detectable power. Recent use of $\mathrm{H}_{2}+\mathrm{Ni}$ to generate large power begs the question of how protons might generate energy by fusion or how transmutation of nickel might be the source. Proposed explanations have been published (Storms 2013) but are too complex to discuss here. Although changes in isotopic ratio are occasionally reported and elements not previously detected are found after power is made, none of these observations have a quantitative relationship to power production.

In conclusion, numerous efforts to find an explanation are underway and are being tested. The phenomenon has novel features, it is not in conflict with any law of nature, and it is not caused by the well-known mechanism that produces hot fusion. An explanation must at least be consistent with laws known to apply to a chemical system and it must explain all observed behavior. Most explanations fail these two requirements and many others. A new window into understanding nuclear interaction has opened and must be explored using the best information available, which the review under discussion attempted to provide.

\section{References}

Krivit S (2013) Nuclear phenomena in low-energy nuclear reaction research. Naturwissenschaften 100(9):899-900

Srinivasan M, Miley G, Storms E (2011) Low-energy nuclear reactions: transmutations. In: Krivit SB, Lehr JH, Kingery TB (eds) Nuclear energy encyclopedia: science, technology, and applications. John Wiley \& Sons, Hoboken, pp 503-509

Storms EK (2007) The science of low energy nuclear reaction. World Scientific, Singapore

Storms EK (2010) The status of cold fusion (2010). Naturwissenschaften 97:861-881

Storms EK (2013) The role of voids as the location of LENR. J Cond Matter Nucl Sci 11:123-141 